Jasmin Sehovic

Ivan Filipovic

Boran Pikula

https://doi.org/10.21278/TOF.44202

ISSN 1333-1124

eISSN 1849-1391

\title{
EXPERIMENTAL DETERMINATION OF NON-LINEAR CHARACTERISTICS OF THE PASSENGER VEHICLE SUSPENSION SYSTEM
}

\begin{abstract}
Summary
The vehicle suspension system is supposed to provide comfort to the driver and to passengers, as well as to ensure the vehicle stability, especially while driving through curves, i.e. while cornering. Simulation is frequently used to analyse the vehicle behaviour under various driving conditions. When defining a physical model of a suspension system, as the initial step in the simulation program development, it is important to determine, as precisely as possible, the following key parameters: mass, mass moments of inertia, stiffness, damping properties of the material, damping of elastic vehicle parts (stabilisers, tyres), damping properties of particular vehicle dampers, damping of joints and links as individual components of the suspension system, as well as other characteristics.

A telescopic damper is an essential part of the suspension system. Its damping properties are highly non-linear. Most publications deal with damping in general terms. Specific data is usually not provided. This paper is, however, focused on determining both the magnitude and the character of damping. A methodology that combines experiment and calculation has been developed for that purpose. As part of the experiment, kinematics (accelerations) at characteristic positions of the suspension system is first determined. By combining a onedimensional (1D) mathematical model and experimental results, the instantaneous values of damping force and the magnitude of damping coefficient, as a function of the piston velocity and the travel of the telescopic damper, were determined. The suspension system of an inproduction passenger vehicle is investigated using a combined analytical and experimental method. The results of real damping and of damping coefficients are presented.

Finally, the results of the simulation, created by using the parameters determined in the previous step, and of the experiment were compared.
\end{abstract}

Key words: $\quad$ Vehicle oscillations, telescopic damper, damping coefficient

\section{Introduction}

In real-life conditions, the vehicle motion is always accompanied by oscillations. Oscillations are the cause of the driver's and passengers' fatigue; in addition, they exert additional load to the vehicle and to the road. The suspension system and the tyres affect the vehicle oscillation most significantly [1]. This is why a precise determination of the properties of the suspension system components is essential. 
Whether it is commercial or self-developed, simulation software is the most convenient tool for investigating oscillations of the entire suspenison system (sprung mass and unsprung mass). Simulation programms are based on various physical models [9]. Particular parameters of a physical model (mass, stifnesses, damping) are determined either numerically [4], or experimentally [5], or by using a combined numerical and experimental method.

As already pointed out, a telescopic damper is the essential component of the suspension system. It is well known that its damping characteristic is highly non-linear. A damping characteristic may be defined in several ways:

- by linearisation. Damping coefficient $\left(\bar{k}_{v}\right)$, as the coefficient of linearity, is introduced. Typically, its value is determined based on experience;

- by developing a specific and detailed hydrodynamic model of a telescopic damper. Such a model is supposed to provide flow discharge coefficients and effective flow cross sectional areas; and

- by experiment. Non-linear damping characteristics are indirectly obtained as a function of travel of the telescopic damper piston.

The latter method from the above list yields the most reliable results. The accuracy of the results depends on the quality of both the experimental equipment and the analysis. The aim of this paper is to present an indirect method of determining the non-linear damping characteristic as a function of the travel of the telescopic damper piston. A combination of the suspension system 1D model [9] and measurements is used for that purpose.

\section{Analysis of Investigation Results}

The experimental method proposed in this research requires the placing of transducers on three characteristic positions of the suspension system. An excitation device, which is the standard equipment used for the inspection of telescopic dampers in the vehicle inspection stations, is used.

Calculation of the telescopic damper characteristics is based on the mathematical model described below. Once the calculation procedure is explained, the details of the experiment are described. At the end, results of the experiment carried out on an in-production vehicle are shown along with the calculation results.

\subsection{A Physical and a Mathematical Model}

Having in mind the main aim of this investigation, the oscillation model of a quarter of the vehicle [9] was selected. Figure 1 shows an example of the model. As proposed in [10], damping within the tyre $\left(k_{t}\right)$ is neglected here.

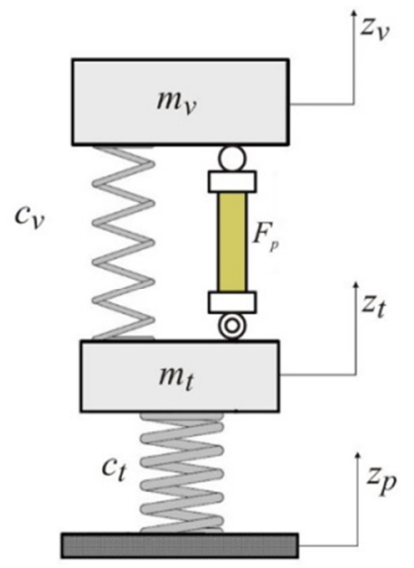

Nomenclature:

$c_{t}-$ stiffness of the tyre

$c_{v}$ - spring stiffness

$F_{p}$-damping force within the telescopic damper

$m_{t}$ - mass of the wheel

$m_{v}$ - mass of the vehicle body per single wheel

$z_{p}-$ travel of the excitation device

$z_{t}$ - travel of the unsprung mass (wheel)

$z_{v}$ - travel of the sprung mass (vehicle body)

Fig. 1 A physical model of a quarter of the vehicle [9] 
The oscillation system in Figure 1 may be described mathematically as:

$$
\begin{aligned}
& m_{v} \ddot{z}_{v}+F_{p}+c_{v}\left(z_{v}-z_{t}\right)=0, \\
& m_{t} \ddot{z}_{t}-F_{p}+c_{v}\left(z_{t}-z_{v}\right)+c_{t}\left(z_{t}-z_{p}\right)=0 .
\end{aligned}
$$

Equations (1) and (2) are of the type of ordinary, linear, differential equations. Here, it is assumed that the damping force is linear. It is described as:

$$
F_{p}=\bar{k}_{v}\left(\dot{z}_{t}-\dot{z}_{p}\right)=\bar{k}_{v} \dot{z}_{k}
$$

where $\dot{z}_{k}$ is the damper piston velocity, and $\bar{k}_{v}$ is the damping coefficient, which is constant. However, in reality, the damping force is highly non-linear, $F_{p}=k_{v} \dot{z}_{k}$, as explained in [10].

Using the experimental results of kinematics at the characteristic positions of the suspension system (acceleration - measured directly, velocity and travel - determined indirectly, integrated from acceleration), a new approach to the determination of the damping force, $F_{p}$, is proposed in this paper. Once the damping force is determined, it becomes possible to calculate the mean value of the damping coefficient, $\bar{k}_{v}$, as well as to figure out the realistic character of the damping coefficient $k_{v}$.

\subsection{Equipment and Results of the Experiment}

As already mentioned, the standard equipment used for telescopic damper inspection in vehicle inspection stations, is used as an excitation device in this experiment. Excitation is created in a controlled manner, during a prescribed period. Transducers are placed on three characteristic positions: 1) on the excitation device, 2) on the specific position on the unsprung mass (wheel lower arm), and 3) on the specific position on the sprung mass (vehicle body). Transducers are actually accelerometers. Placing the transducers in a constrained space was a significant challenge. This is why relatively small, but capable, three-axial SLAM STICK transducers, made by Mide Technology (USA), were selected. A picture of a transducer and its technical specifications are shown in Figure 2.
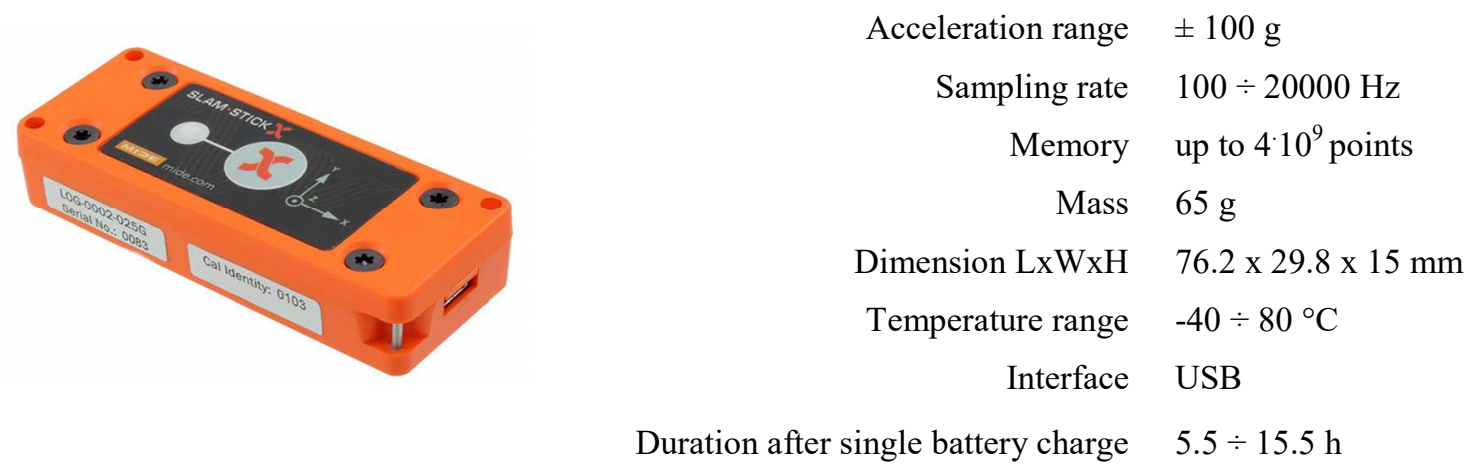

Fig. 2 Three-axial accelerometer

It was necessary to define the excitation for concrete measurements, which provides realistic quality oscillations of vehicle over a period of time. Thus, it was decided to generate excitation by artificial means using a telescopic damper testing device at vehicle inspection stations.

Figure 3 shows the positions of transducers installed on the vehicle. The vehicle used for the experiment was a Dacia Duster $1.5 \mathrm{dCi} 4 \mathrm{WD}$. The specifications of the vehicle are: mass of empty vehicle - $1405 \mathrm{~kg}$, 6-gear manual transmission, MacPherson strut with lower 
lateral arms and stabilisers on the front, and a flexible axle with coil springs and dampers in the rear. Laboratory tests carried out at the Mechanical Engineering Faculty in Sarajevo, resulted in a spring stiffness of $c_{v}=45000 \mathrm{~N} / \mathrm{m}$, and a radial stiffness of the tyre of $c_{t}=250000 \mathrm{~N} / \mathrm{m}$.

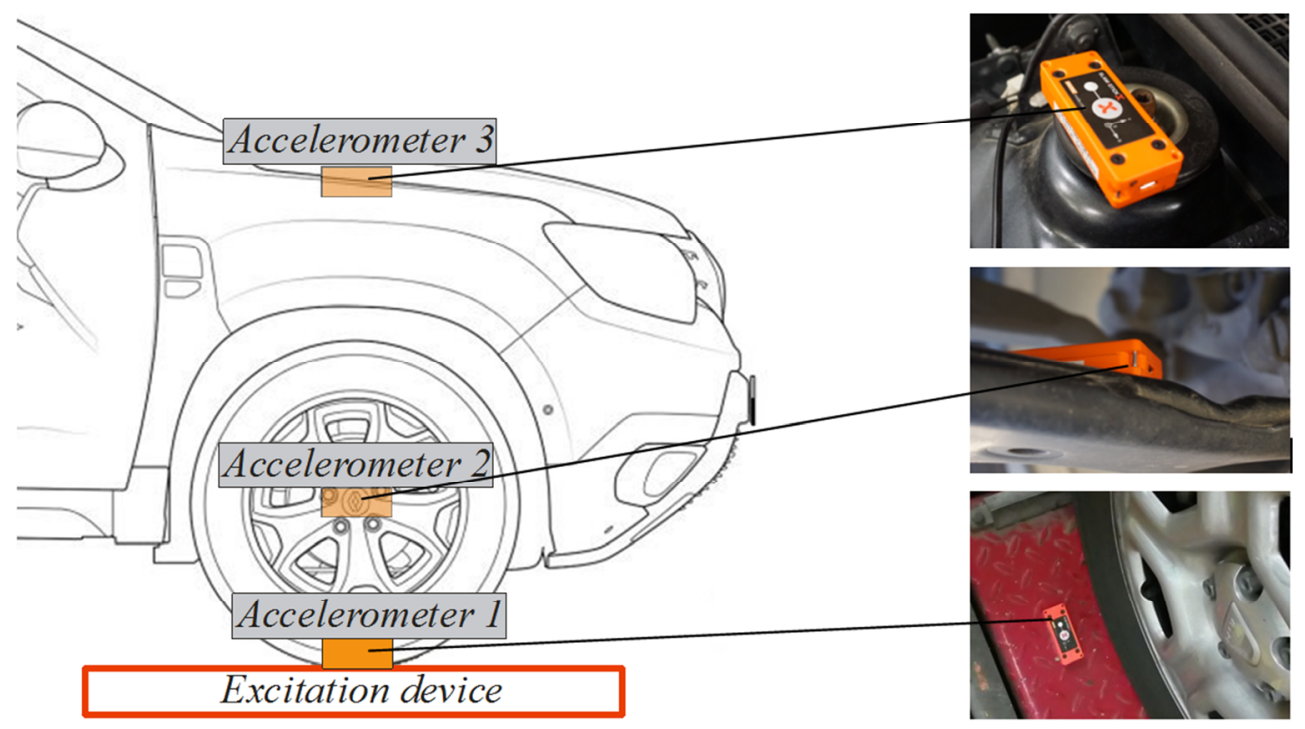

Fig. 3 Positions of accelerometers

Figure 3 shows accelerometer 1 placed on the excitation device. Other two accelerometers were placed on the characteristic positions of the suspension system, accelerometer 2 on the lower arm, and accelerometer 3 on the vehicle body. The sampling rate was set to $5000 \mathrm{~Hz}$. The excitation device frequency was set to about $10 \mathrm{~Hz}$. Signals were synchronised in relation to the signal from the excitation device. The excitation duration was set to about $17 \mathrm{~s}$. All three signals (accelerations), i.e. from the excitation device $\left(\ddot{z}_{p}\right)$, the lower $\operatorname{arm}\left(\ddot{z}_{t}\right)$, and the vehicle body $\left(\ddot{z}_{v}\right)$, are shown on a single diagram. Figure 4 shows the results in $1 \mathrm{~s}$ periods $(t)$.

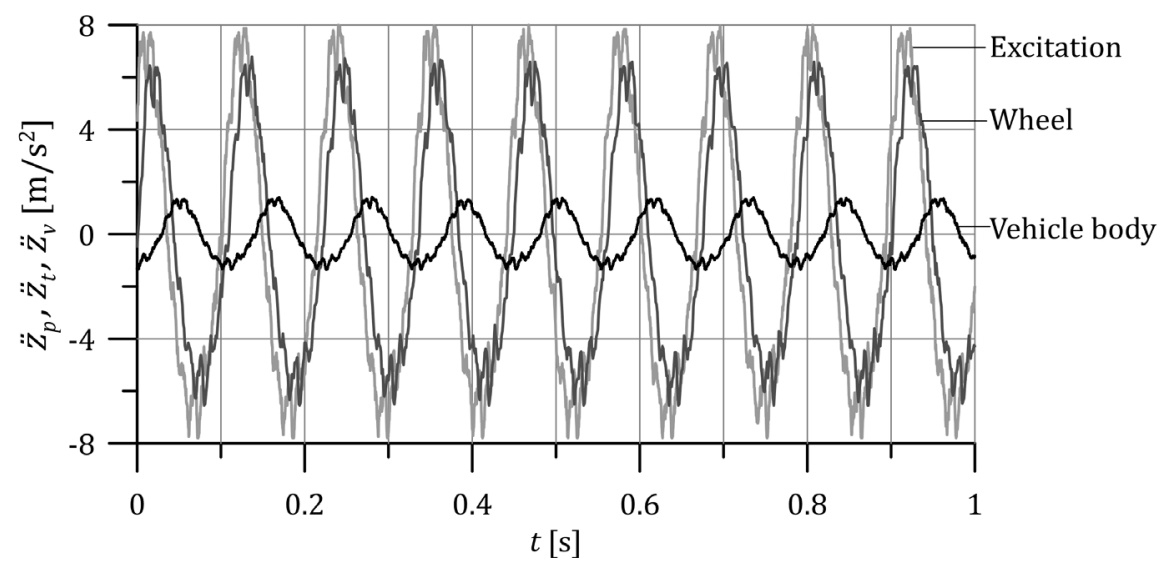

Fig. 4 Measured accelerations

Results were further analysed in one oscillation period of $0.118 \mathrm{~s}$. Due to the high sensitivity of transducers, higher oscillation orders were also registered. These higher orders are due to variable stiffness and variable damping of the suspension system parts. Higher orders were neglected in the physical and mathematical models. A comparison between experimental results and the results obtained after harmonic analysis of measured signal is shown in Figure 5. 

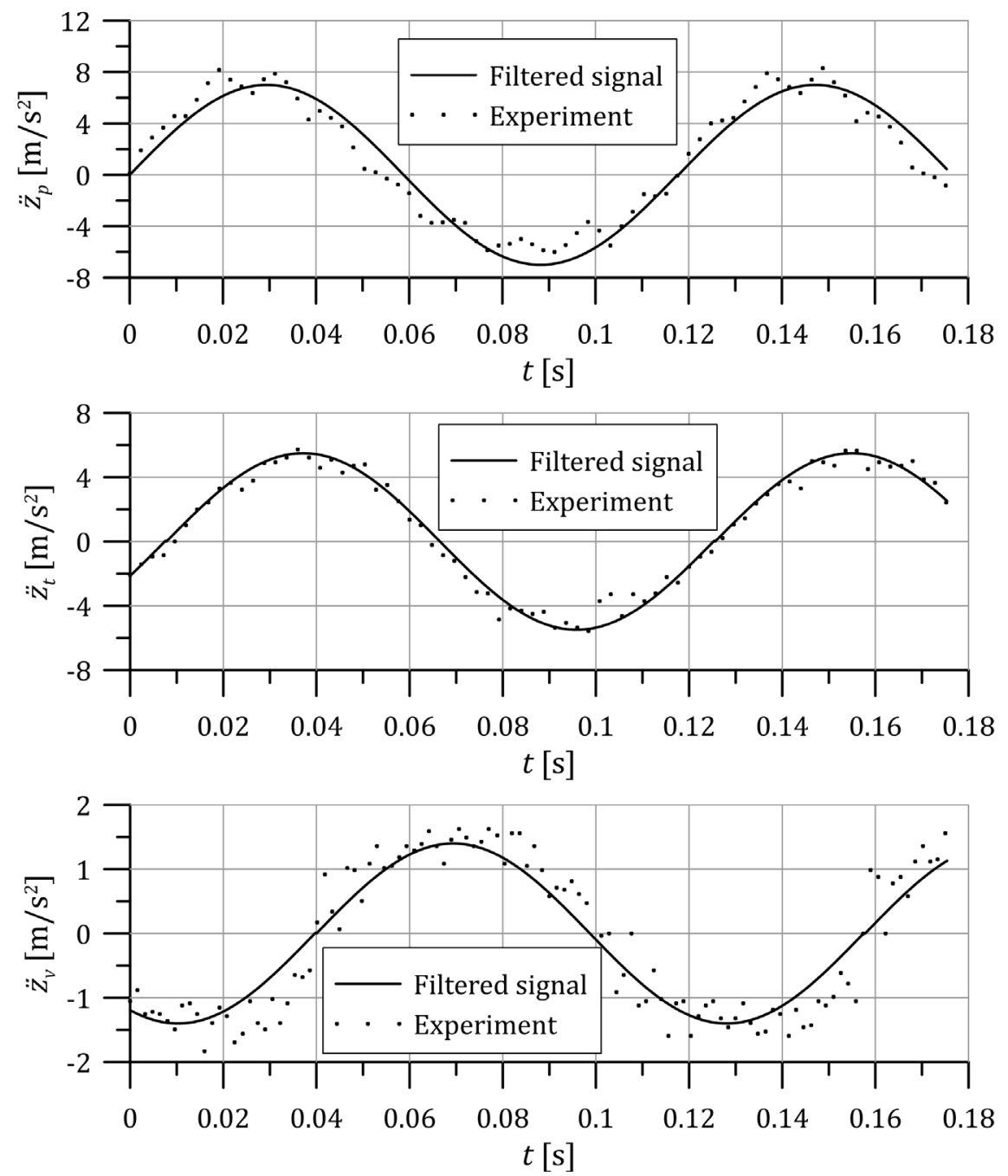

Fig. 5 Comparison between the measured signal and the results of harmonic analysis

The solid line in Figure 5 shows the results of harmonic analysis. Its frequency corresponds to excitation frequency. Higher oscillation orders were neglected here due to considerable complexity of the suspension system design and its physical properties. At the same time, the inclusion of high orders would add to the complexity of the physical model. The authors' opinion is that the simple model shown in Figure 1 provides results which are accurate enough, and therefore, a higher level of complexity seems useless and unnecessary.

The results of accelerations obtained by harmonic analysis are shown in Figure 6 for one excitation cycle (one period). Due to the harmonic character of accelerations (Figure 6), the further analysis is simplified.

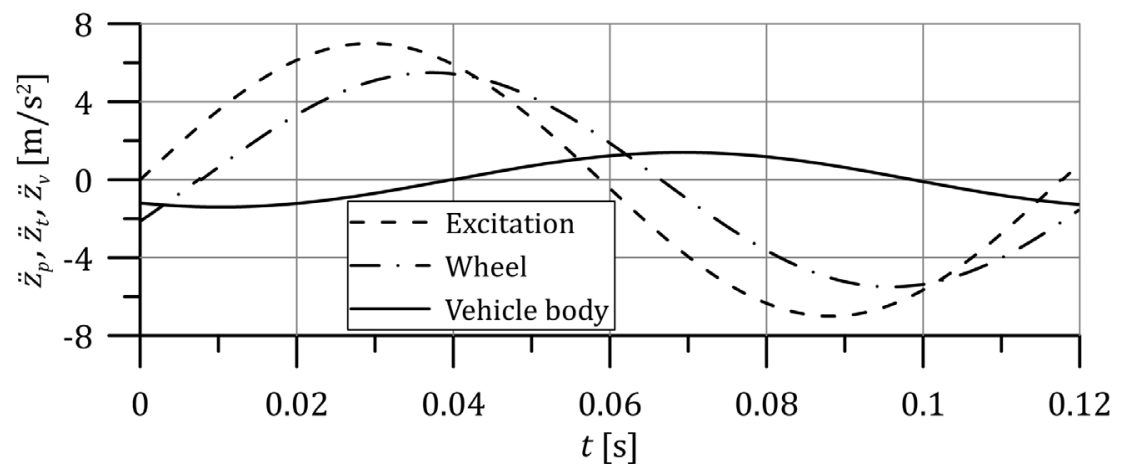

Fig. 6 Accelerations after harmonic analysis 
After integrating the accelerations shown in Figure 6, the velocities and the travel of excitation $\left(\dot{z}_{p}, z_{p}\right)$, wheel $\left(\dot{z}_{t}, z_{t}\right)$, and vehicle body $\left(\dot{z}_{v}, z_{v}\right)$ are obtained and shown in Figures 7 and 8.

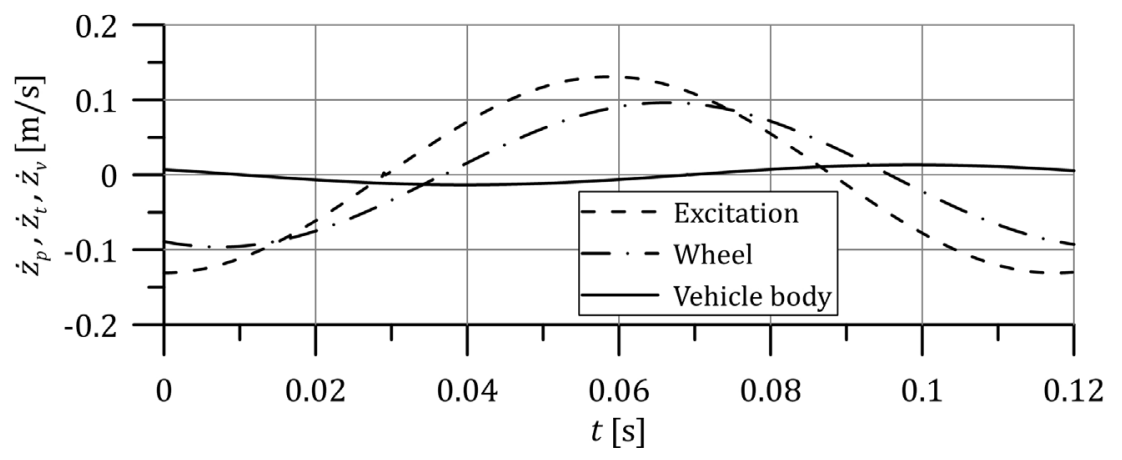

Fig. 7 Oscillation velocity of excitation, wheel, and vehicle body

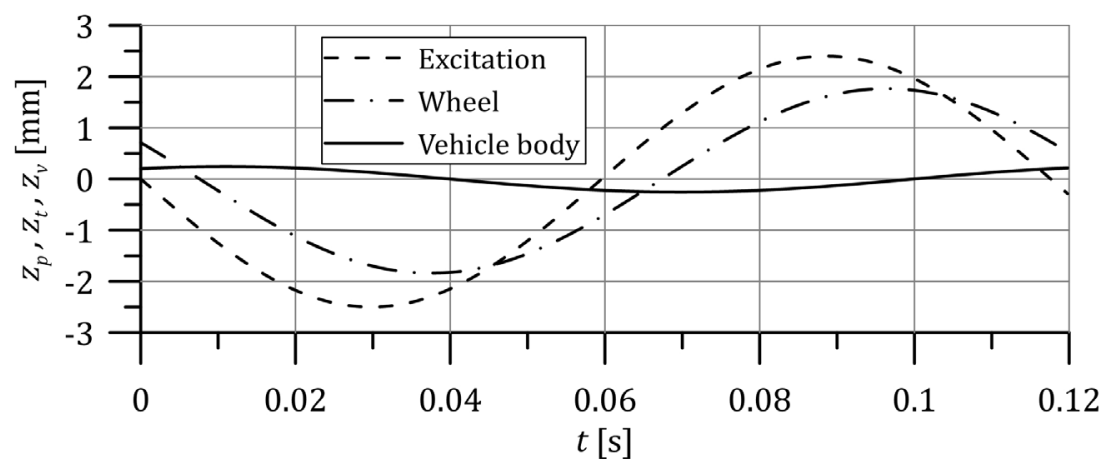

Fig. 8 Travel of excitation device, wheel and vehicle body during one period of oscillation

Now, by combining the results of measured accelerations of the excitation device, the wheel and the vehicle body (Figure 4), with those of velocities (Figure 7) and travels (Figure 8), and by applying equations (1), (2), and (3), the calculation of the damping force $\left(F_{p}\right)$ is made possible.

Figure 9 shows the damping force, $F_{p}$, versus time during one oscillation period. The diagram in Figure 9 is obtained by calculation, using equation (1) or equation (2). Next, based on the known velocity of the telescopic damper piston, $\dot{z}_{k}=\dot{z}_{t}-\dot{z}_{v}$, and knowing the damping force from Figure 9, it becomes possible to define their relationship, as shown in Figure 10. The elliptical shape of this relationship is well known in the relevant literature.

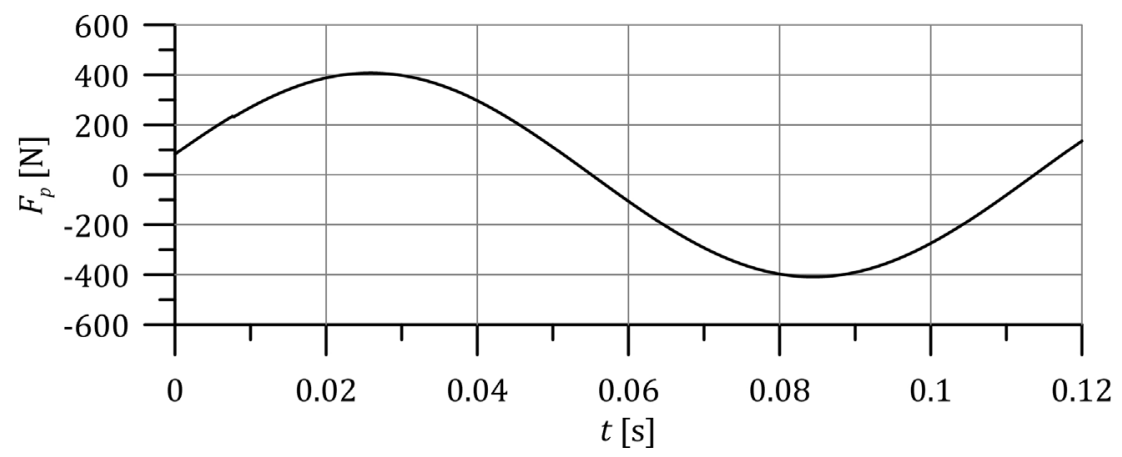

Fig. 9 Changes in the damping force during one oscillation period

Finally, it was possible to figure out the relation between the instantaneous damping, $k_{v}$, and the travel of telescopic damper piston, $z_{k}=z_{v}-z_{t}$. This relation is shown in Figure 11. 


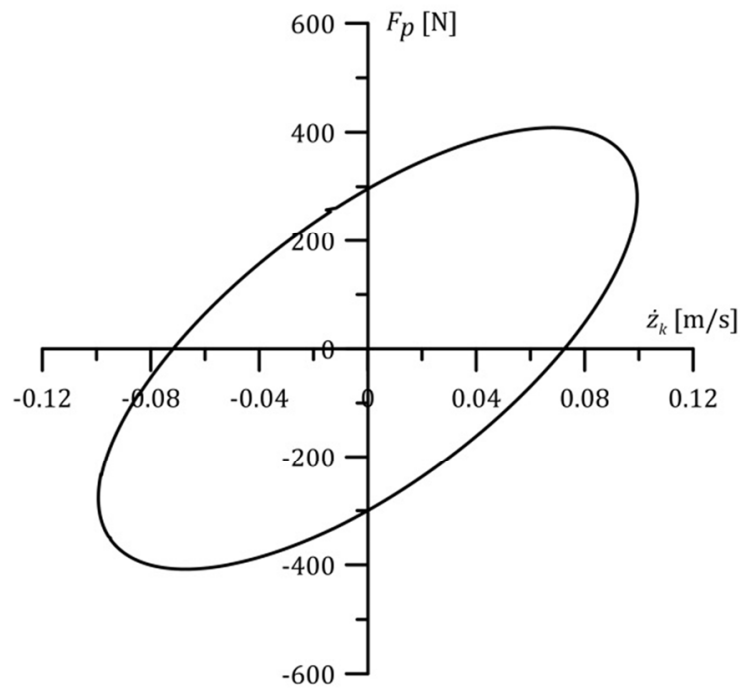

Fig. 10 Damping force, $F_{p}$, as a function of the damper piston velocity, $\dot{z}_{k}$

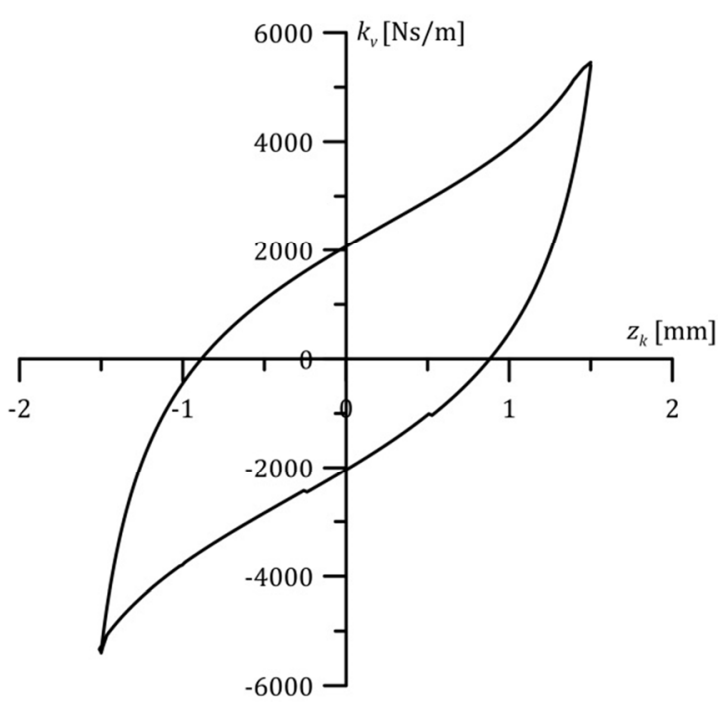

Fig. 11 Damping, $k_{v}$, as a function of the damper piston travel, $z_{k}$

Now, the initial mathematical model (equations (1) and (2)) may be improved by using the values of the damping force and the damping coefficient from Figures 10 and 11. For the family of telescopic dampers of similar design, it is proposed to make all relevant relations more general, i.e. dimensionless. Therefore, the dimensionless damping coefficient, $k_{v r}=\frac{k_{v}}{k_{v \max }}$, and the dimensionless piston travel, $z_{k r}=\frac{z_{k}}{z_{k \max }}$, are shown in relation to the maximum damping coefficient $\left(k_{v \max }\right)$ and to the maximum piston travel $\left(z_{k \max }\right)$. With these propositions, and based on the results from Figure 11, the mathematical model can be expanded by a correlation that approximates the experimental results from Figure 11:

$$
k_{v r}=a\left|z_{k r}\right|^{c}+b \text {, }
$$

Constants in equation (5) are:

$$
\begin{aligned}
& a=-1.4 ; \quad b=+0.4 ; c=+2.4 \text { if } \dot{z}_{k}>0 \text { and } z_{k}<0 \text {, } \\
& a=+1.4 ; \quad b=-0.4 ; c=+2.4 \text { if } \dot{z}_{k}<0 \text { and } z_{k}>0 \text {, } \\
& a=+0.6 ; b=+0.4 ; c=+1.6 \text { if } \dot{z}_{k}>0 \text { and } z_{k}>0 \text {, } \\
& a=-0.6 ; \quad b=-0.4 ; c=+1.6 \text { if } \dot{z}_{k}<0 \text { and } z_{k}<0 \text {. }
\end{aligned}
$$

After equation (5) is introduced into equations (1) and (2), and $k_{v}$ and $z_{k}$ are replaced with $k_{v}=k_{v r} / k_{v \max }$ and $z_{k}=z_{k r} / z_{k \max }$, respectively, the final and complete mathematical model that describes the physical model in Figure 1 was obtained. Now, it is a system of nonlinear, ordinary differential equations of the second order. This system of equations may be solved numerically. For the example used in this paper, it was found that $k_{\text {vmax }}=5400 \mathrm{Ns} / \mathrm{m}$.

Besides the approximation shown in equation (5), the authors propose the following approximation:

$$
\frac{\left(z_{k r}+k_{v r}\right)^{2}}{a_{1}}+\frac{\left(z_{k r}-k_{v r}\right)^{2}}{b_{1}}=1 .
$$

Equation (6) is actually the equation of ellipse. For the example described in this research, the numerical values of constants in equation (6) are: $a_{1}=4$ and $b_{1}=0.166$. If telescopic dampers are of the same design, the maximum values remain unchanged. The approximation from equation (6) and the experimental results are not that well matched as the approximation from equation (5). However, equation (6) is used in literature more often. 
The mathematical model can be simplified if the damping coefficient of the telescopic damper is linearized. For that purpose, it is necessary to define the elastic work $\left(W_{e l}\right)$ and the damping work $\left(W_{p}\right)$, which can both be determined from the damping force, $F_{p}$, and the travel of the damper piston, $z_{k}$. In reference [11], the relative damping, $\psi_{r}$, is defined as the ratio of the damping work to the elastic work as:

$$
\psi_{r}=\frac{W_{p}}{W_{e l}}
$$

Further, by knowing the relative damping, $\psi_{r}$, according to [11], it is possible to define Lehr's measure of damping as:

$$
\xi_{r}=\frac{\psi_{r}}{4 \pi} .
$$

Based on expressions (7) and (8), and according to [10, 11], the damping coefficient, $\bar{k}_{v}$, may be defined as:

$$
\bar{k}_{v}=2 m_{v} \omega_{0} \xi_{r}=2 \sqrt{m_{v} c_{v}} \xi_{r},
$$

where $\omega_{0}$ is the natural frequency of oscillation.

After calculating the damping work $\left(W_{p}\right)$ and the elastic work $\left(W_{e l}\right)$ from experimental results, and after using equation (9), the value of the damping coefficient of the telescopic damper was calculated as $\bar{k}_{v}=2197 \mathrm{Ns} / \mathrm{m}$.

The proposed model of damping was further verified by running a $1 \mathrm{D}$ simulation. For that purpose, the damping coefficient of the telescopic damper was defined by equation (5), and by equation (9) for the mean value $\left(\bar{k}_{v}\right)$.

Figure 12 shows a comparison between the measured and simulated accelerations of the wheel $\left(\ddot{z}_{t}\right)$ and the vehicle body $\left(\ddot{z}_{v}\right)$ during one period of oscillation. The simulation was run in both ways of calculating the damping coefficient proposed here, i.e. first, using equation (5), and then, using equation (9). The agreement between the experiment and the simulation is considered as satisfactory.
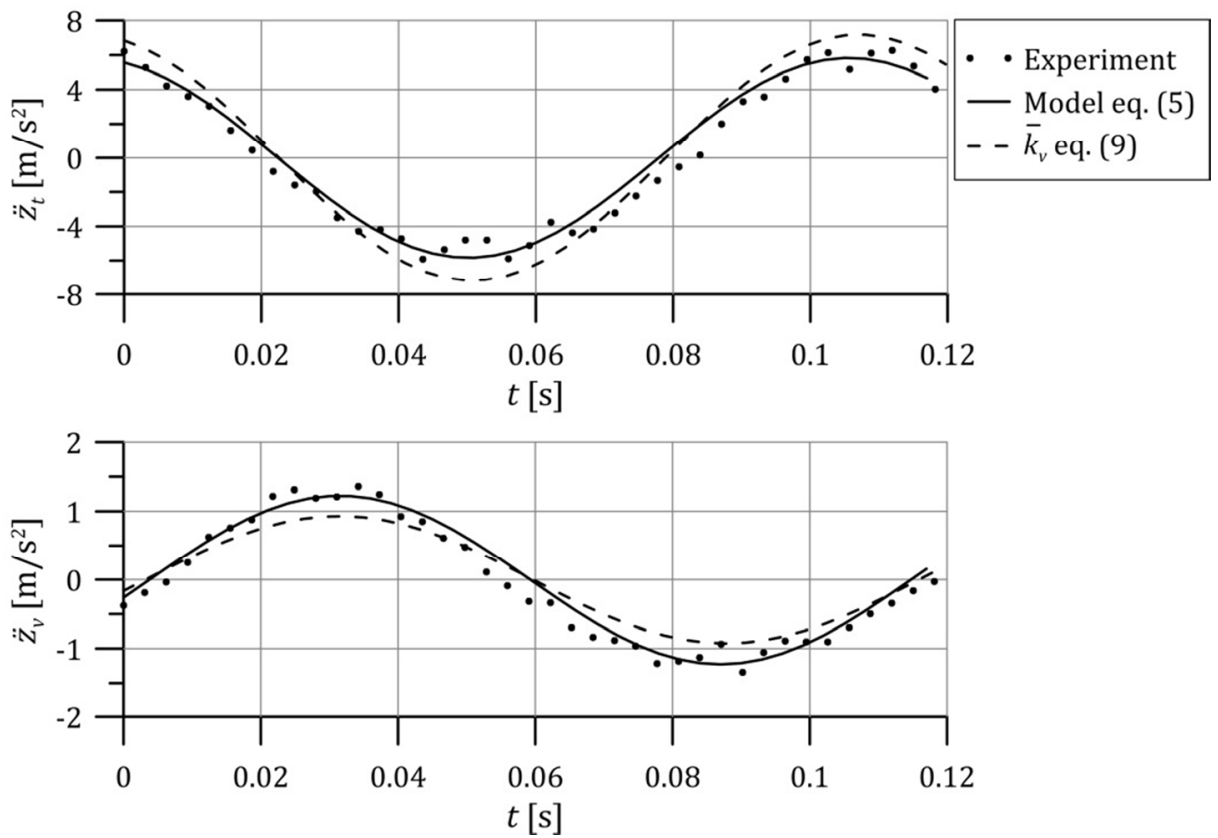

Fig. 12 Comparison between the measured and the simulated accelerations of the wheel $\left(\ddot{z}_{t}\right)$ and the vehicle body $\left(\ddot{z}_{v}\right)$ 
To sum up, the method proposed in this paper enables us to determine the mean value of the damping coefficient of a non-linear damping component of the vehicle suspension system.

\section{Conclusions}

This paper describes a combined experimental and analytical method of determining the damping characteristic of a telescopic damper. The advantage of the proposed method is that the suspension system needs not to be disassembled. Measuring equipment consists of three accelerometers and an oscillation excitation device. Such a device is often used as standard equipment in vehicle inspection stations.

Telescopic damper characteristics were calculated based on simple physical and mathematical models in combination with the measurement of accelerations on three positions. Results are shown in the following forms:

- damping force as a function of the velocity of the telescopic damper piston,

- damping coefficient as a function of the travel of the telescopic damper piston, and

- mean value of the damping coefficient.

The proposed method was employed on an in-production vehicle. The agreement between the calculated and the measured results proves that the proposed method is a useful tool. It enables us to characterise the telescopic damper in a simple and timely manner, without removing it from the vehicle.

\section{REFERENCES}

[1] Richard Stone and Jeffrey K. Ball, Automotive Engineering Fundamentals, SAE International, 2004

[2] Nan Marin-Silviu et al., Research on the construction and function of the road vehicles suspension systems, International multidisciplinary symposium Universitaria SIMPRO 2014, University of Petrosani, October 10-11 2014

[3] https://www.kyb.com/knowledge-center/shock-tech-for-pros/monotube-vs-twintube/

[4] A. G. Hejib, R. L. Mankar, Experimental analysis of helical compression spring use in two wheeler suspension system, International Journal of Advanced Research in IT and Engineering, Vol-3 Issue-4, 2017

[5] M. Izaham Zainal Abidin et al., Experimental and Numerical Investigation of SUP12 Steel Coil Spring, The Malaysian International Tribology Conference 2013, MITC2013, 2013

[6] Vidas Žuraulis et al., Development and verification of a shock absorber and its shim valve model based on the force method principles, Eksploatacja i Niezawodnosc - Maintenance and Reliability, December 2016. https://doi.org/10.17531/ein.2017.1.18

[7] Shaohua Li, Yongjie Lu and Liyang Li, Dynamical Test and Modelling for Hydraulic Shock Absorber on Heavy Vehicle under Harmonic and Random Loadings, Research Journal of Applied Sciences, Engineering and Technology 4(13):1903-1910, 2012 ISSN: 2040-7467, Maxwell Scientific Organization, 2012

[8] Ivan Filipović, Cestovna vozila, ISBN-978-9958-601-34-7, Mašinski fakultet Sarajevo, 2012

[9] Georg Rill, Vehicle Dynamics, Hochschule Regensburg, University of Applied Science, 2009

[10] John C. Dixon, The Shock Absorber Handbook, John Wiley and Sons, 2007

[11] Ivan Filipović, Dževad Bibić, MOTORI S UNUTRAŠNJIM SAGORIJEVANJEM - Torzione oscilacije, ISBN 978-9958-601-51-4, Mašinski fakultet Sarajevo, 2015

[12] Clarence W. de Silva, Vibration Damping, Control and Design, Taylor \& Francis Group, LLC, 2007

[13] Reza N. Jazar, Vehicle Dynamics - Theory and Application, $3^{\text {rd }}$ edition, Springer International Publishing AG, 2017

[14] Anil Antony Sequeira, Ram Kishan Singh, Ganesh K. Shetti, Comparative Analysis of Helical Steel Springs with Composite Springs Using Finite Element Method, Journal of Mechanical Engineering and Automation, 6(5A): 63-70, 2016 
